\title{
EFFECT OF RENAL SPECIFIC ORAL NUTRITION (ONCE RENAL) ON DIETARY INTAKE AND SERUM ELECTROLYTES IN CHRONIC KIDNEY DISEASE STAGE IV
}

Bancha Satirapoj*, Narittaya Varothai*, Natthida Boonyagarn"*, Yanisa Pumsutas ${ }^{* *}$, Samitti Chotsriluecha**, Ouppatham Supasyndh*

"Division of Nephrology, Department of Medicine, Phramongkutklao Hospital and Phramongkutklao College of Medicine, Bangkok, Thailand

** Division of Clinical Nutrition, Department of Medicine, Phramongkutklao Hospital and Phramongkutklao College of Medicine, Bangkok, Thailand

\begin{abstract}
Background and Objective: Low nutritional intake is common in advanced chronic kidney disease (CKD) and poses a direct risk for malnutrition. Our study evaluated the effects of a renal specific oral nutrition (ONCE Renal) supplement concerning nutritional status, minerals and electrolytes among patients with stage IV CKD.

Methods: A total of 32 patients with CKD with an estimated glomerular filtration rate $16-29 \mathrm{~mL} /$ $\min / 1.73 \mathrm{~m}^{2}$, well-nourished subjects and anticipated good compliance with the diet received the ONCE Renal diet instead of 1 meal daily for 30 days. Dietary protein and energy intake, body compositions, and serum concentrations of urea, creatinine, calcium, magnesium, phosphate and albumin were assessed at baseline, and at 30 days. A dietary intake by three-day food record was also evaluated by a registered dietitian.

Results: At the end of 30 days, significant improvements in energy, fat, fiber and magnesium intake by dietary interview were noted. In addition, the patients also increased body weight and body mass index after supplement. No significant changes in renal function, serum electrolytes, calcium, phosphorus, magnesium concentration and other nutritional markers including serum albumin, body compositions and protein equivalence of total nitrogen appearance were observed during study. The compliance with the ONCE Renal diet was good among enrolled patients and no adverse reactions were found.

Conclusion: Renal specific oral diet supplement can improve energy intake, body weight and maintain serum electrolyte concentrations among patients with stage IV CKD.
\end{abstract}

Keywords: Renal specific oral nutrition, Low protein diet supplement, Chronic kidney disease, Serum electrolytes, Nutritional status

J Southeast Asian Med Res 2020; 4(1):7-15

http://www.jseamed.org

Correspondence to:

Satirapoj B., 315, Division of Nephrology, Department of Medicine, Phramongkutklao Hospital and Phramongkutklao College of Medicine, Bangkok 10400 Thailand

Phone: 662-6444676; Fax: 662-6444676;

Email: satirapoj@yahoo.com

Received: 14 November 2019

Revised: 24 December 2019

Accepted: 5 January 2020 


\section{INTRODUCTION}

Malnutrition and chronic inflammatory state are common among patients with advanced chronic kidney disease (CKD) and are associated with increased hospitalization and mortality rates. ${ }^{(1,2)}$ Strong relationships exist among malnutrition, inflammation and atherosclerosis in CKD. The major causes of malnutrition in CKD include reduced food intake and appetite due to effects of uremia, reduced absorption of nutrients, metabolic acidosis, increased protein loss from chronic inflammation and oxidative stress. $^{(3,4)}$

Suboptimal dietary intake and resting energy expenditure is increased among patients with advanced CKD and hemodialysis with severe hyperparathyroidism. ${ }^{(5-7)}$ Therefore, these populations are susceptible to insufficient energy intake with energy intakes below $30 \mathrm{kcal} / \mathrm{kg} / \mathrm{day}{ }^{(8)}$ Oral nutritional supplementation is one of treatment options in these populations. Specific renal diets, designed to increase caloric and fiber intake without high protein, electrolytes and mineral load, are expected to improve energy intake and nutrition status without significant electrolyte abnormality.

Early evaluation and intervention concerning dietary intake may help to prevent malnutrition and CKD progression before and after commencing renal replacement therapy. Currently, dietary supplements among patients with advanced CKD can be challenging to health care teams and patients. Most patients with advanced CKD and undergoing hemodialysis have lower than normal dietary energy intake, and oral nutrition supplements are further needed to achieve intake recommendations. ${ }^{(9,10)}$ Currently, no consensus guidelines exist on the specific type of oral nutrition supplements and dietary approaches mentioned and strong evidence remains lacking. ${ }^{(11)}$ This study aimed to determine the effects of a renal specific oral nutrition (ONCE Renal) diet on biochemical intake, calcium, magnesium, phosphate metabolism, nutrition markers and compliance with the prescribed diet among patients with advanced CKD for 30 days.

\section{MATERIALS AND METHODS}

Our prospective interventional study was conducted at Phramongkutklao Hospital, Bangkok, Thailand, from August to December 2018. All patients were recruited from the outpatient center, examined by the same physician and counseled by the same registered dietitian during the study. This project was approved by the institutional review board of the Royal Thai Army Medical Department (S005h/61) and conducted in accordance with the Declaration of Helsinki. Informed consent was obtained from participants.

Inclusion criteria for subjects with CKD aged 18 to 75 years was estimated glomerular filtration rate (eGFR) of 15 to $29 \mathrm{~mL} / \mathrm{min} / 1.73 \mathrm{~m}^{2}$ (stages 4 CKD) and those who had $<10 \%$ change in GFR within 3 months, well-nourished subjects (Subjective GlobalAssessment score A/B and serum albumin $\geq 3.5 \mathrm{~g} / \mathrm{dL}$ ) and consented to participate in the study. Patients with CKD with active malignancy, severe heart, lung or liver disease, chronic HIV, hepatitis B virus or hepatitis $\mathrm{C}$ virus infection, malnourished conditions defined as a loss of $\geq 5 \%$ body weight over the past 3 months or serum albumin concentration $<3.5 \mathrm{~g} / \mathrm{dL}$ were excluded from the study.

Baseline information including age and sex of participants was obtained. All participants were interviewed, physically examined, and investigated for underlying medical illness. Weight was measured using a weighing scale and height was measured using a stadiometer to the nearest centimeter with subjects before and after treatment. The body mass index (BMI) was calculated using the formula: Weight $/(\text { Height })^{2}$ $\left(\mathrm{kg} / \mathrm{m}^{2}\right)$. Casual systolic blood pressure (SBP) and diastolic blood pressure (DBP) were measured using a standard mercury sphygmomanometer applied on the same arm after a 10-minute rest in the sitting position.

About $7 \mathrm{~mL}$ of venous blood after an 8-hour fast was obtained from patients to perform biochemical tests including fasting plasma concentrations of blood urea nitrogen (BUN), creatinine, electrolytes, calcium, phosphorus, magnesium and albumin before and after treatment. All participants performed self-directed 24-hour urine collections for protein, sodium, potassium, magnesium and chloride. Serum and urine creatinine samples were analyzed using the enzymatic method. GFR, using the CKD-EPI equation based on serum creatinine, was calculated. 
Table 1. Contents of the ONCE Renal Supplement

\begin{tabular}{|c|c|}
\hline Macronutrient & 1 serving or $76 \mathrm{~g}(360 \mathrm{kcal})$ \\
\hline \multicolumn{2}{|l|}{ Caloric Distribution of Macronutrients (\%) } \\
\hline - Protein & $8 \%$ \\
\hline - Carbohydrate & $52 \%$ \\
\hline - Fat & $40 \%$ \\
\hline \multicolumn{2}{|l|}{ Source } \\
\hline Protein & $7.19 \mathrm{~g}$ \\
\hline 1. Casein & $3.595(50 \%)$ \\
\hline 2. Soy protein isolate & $3.595(50 \%)$ \\
\hline Carbohydrate & $48.25 \mathrm{~g}$ (fiber $2.99 \mathrm{~g}$ ) \\
\hline 1. Maltodextrin & $31.3(64.88 \%)$ \\
\hline 2. Isomaltulose & $9.97(20.66 \%)$ \\
\hline 3. Fructose & $3.99(8.27 \%)$ \\
\hline 4. Fibersol & $1.99(4.13 \%)$ \\
\hline 5. Fructooligosaccharides & $1.00(2.06 \%)$ \\
\hline Fat & $15.95 \mathrm{~g}$ \\
\hline 1. Canola oil & $6.98(43.74 \%)$ \\
\hline 2. High oleic safflower oil & $2.99(18.77 \%)$ \\
\hline 3. Medium chain triglycerides oil & $5.98(37.49 \%)$ \\
\hline \multicolumn{2}{|l|}{ Micronutrient } \\
\hline \multicolumn{2}{|l|}{ Vitamins \& Minerals } \\
\hline Vitamin A (mcg RE) & 67.43 \\
\hline Vitamin D (IU) & 15.20 \\
\hline Vitamin C (mg) & 36.27 \\
\hline Calcium, mg & 143.6 \\
\hline Phosphorus, mg & 143.6 \\
\hline Magnesium, mg & 39.06 \\
\hline Potassium, mg & 197.4 \\
\hline Sodium, mg & 132.8 \\
\hline Carnitine, mg & 99.71 \\
\hline Others & As Thai RDI recommendation \\
\hline
\end{tabular}


Body composition was evaluated using direct segmental multi-frequency bioelectrical impedance analysis (DSM-BIA, In-Body (720) body compositions analyzer). The spectrum of electrical frequencies was used to predict the body composition, total fat mass, intracellular (ICW) and extracellular water (ECW) compartments of the total body water (TBW) in the various body segments. Body composition was assessed at baseline and at the end of the study period.

\section{Dietary Intervention}

All participants were provided 360-kcal sachets of ONCE Renal supplement containing $7.19 \mathrm{~g}$ of proteins, $48.25 \mathrm{~g}$ of carbohydrate with fiber $2.99 \mathrm{~g}, 15.95 \mathrm{~g}$ of fat, $143.6 \mathrm{mg}$ of calcium, $143.6 \mathrm{mg}$ of phosphorus, $197.4 \mathrm{mg}$ of potassium and $132.8 \mathrm{mg}$ of sodium (Table 1) instead of 1 meal daily for 30 days. Additional 30 ONCE Renal supplement sachets were provided at first visits, and empty sachets were collected to determine compliance.

All participants kept a 3-day food record and underwent dietary interviews by a registered dietitian, before and after the study period. Nutrient composition of the diets was analyzed using the standard national food database program (Inmucal Version 3.2). Daily protein intake was determined using the calculated protein equivalence of total nitrogen appearance (PNA).

\section{Statistical Analysis}

Data were analyzed using the statistical package for social sciences (SPSS), Version 16.0 (SPSS, Chicago, IL, USA). Continuous variables were presented as means and standard deviation and discrete variables were presented as percentages. Comparisons against the baseline measurements were evaluated using the paired $t$-test while $P$ values $<0.05$ were considered significant.

\section{RESULTS}

We reviewed the eligibility criteria of 62 patients, and 32 patients were recruited during the period of study, consisting of 15 men and 17 women with mean age $66.4 \pm 11.9$ years. Hypertension (84.4\%), dyslipidemia (81.3\%) and type 2 diabetes $(33.3 \%)$ were common comorbid diseases. Baseline participant characteristics are shown in Table 2.

Table 2. Characteristics of the study population

\begin{tabular}{lc}
\hline Characteristics & $\mathbf{N}=\mathbf{3 2}$ \\
\hline Men $(\mathrm{N}, \%)$ & $15(46.9 \%)$ \\
Age $(\mathrm{yr})$ & $66.4 \pm 11.9$ \\
Height $(\mathrm{cm})$ & $161.0 \pm 8.9$ \\
Body weight $(\mathrm{kg})$ & $66.4 \pm 13.6$ \\
Body mass index $\left(\mathrm{kg} / \mathrm{cm}^{2}\right)$ & $25.5 \pm 3.5$ \\
Blood urea nitrogen $(\mathrm{mg} / \mathrm{dL})$ & $34.6 \pm 11.7$ \\
Serum creatinine $(\mathrm{mg} / \mathrm{dL})$ & $2.6 \pm 0.6$ \\
Estimated glomerular filtration rate $\left(\mathrm{mL} / \mathrm{min} / 1.73 \mathrm{~m}^{2}\right)$ & $22.1 \pm 6.0$ \\
Serum albumin $(\mathrm{g} / \mathrm{dL})$ & $4.4 \pm 0.3$ \\
Comorbid disease $(\mathrm{N}, \%)$ & \\
$\quad-\quad$ Diabetes mellitus & $11(33.3 \%)$ \\
$\quad-\quad$ Hypertension & $27(84.4 \%)$ \\
$\quad$ - Gout & $8(24.2 \%)$ \\
\hline
\end{tabular}

Values presented as $n(\%)$ and mean $\pm S D$. 
Table 3. Dietary intake with three-day food record at baseline and the end of one month follow-up

\begin{tabular}{|c|c|c|c|c|c|}
\hline Per day & $\begin{array}{c}\text { Nutritional } \\
\text { Recommendation in } \\
\text { CKD stage III-IV }\end{array}$ & Baseline & End & $\begin{array}{l}\text { Mean Change } \\
(95 \% \mathrm{CI})\end{array}$ & $p$-value \\
\hline Energy (kcal) & - & $1292.9 \pm 392.6$ & $1462.3 \pm 281.1$ & $169.4(57.1$ to 281.7$)$ & 0.004 \\
\hline Energy (kcal/kg/day) & $30-35$ & $19.8 \pm 6.1$ & $22.5 \pm 5.3$ & $2.7(0.9$ to 4.5$)$ & 0.005 \\
\hline Protein (g) & - & $49.2 \pm 15.1$ & $47.4 \pm 15.9$ & $-1.8(-4.2$ to 7.7$)$ & 0.551 \\
\hline Protein (g/kg/day) & $0.6-0.8$ & $0.7 \pm 0.2$ & $0.7 \pm 0.3$ & $0.02(-0.1$ to 0.1$)$ & 0.595 \\
\hline Carbohydrate (g) & - & $190.4 \pm 56.4$ & $201.7 \pm 45.1$ & $11.3(-4.5$ to 23.7$)$ & 0.114 \\
\hline Fat $(g)$ & $\begin{array}{l}\text { Saturated fat }<7 \% \\
\text { Trans fat }<1 \%\end{array}$ & $40.7 \pm 14.9$ & $50.9 \pm 15.2$ & 10.1 (4.9 to 14.3$)$ & $<0.001$ \\
\hline Fiber $(g)$ & $25-38$ & $8.8 \pm 3.2$ & $11.0 \pm 3.7$ & $2.2(0.8$ to 3.2$)$ & $<0.001$ \\
\hline Sodium (mg) & $<2,300$ & $2331.1 \pm 1016.7$ & $2112.6 \pm 1278.1$ & $207.4(-297.9$ to 712.7$)$ & 0.409 \\
\hline Potassium (mg) & $\begin{array}{c}<1,500 \text { with } \\
\text { hyperkalemia }\end{array}$ & $1242.6 \pm 537.7$ & $1219.9 \pm 353.9$ & $29.6(-143.9$ to 203.2$)$ & 0.730 \\
\hline Calcium (mg) & - & $372.7 \pm 171.2$ & $415.5 \pm 198.0$ & $49.1(-123.7$ to 25.6$)$ & 0.190 \\
\hline Phosphorus (mg) & $\begin{array}{c}<800-1,000 \text { with } \\
\text { hyperphosphatemia }\end{array}$ & $518.9 \pm 227.1$ & $600.2 \pm 188.3$ & $81.2(-167.4$ to 5.1$)$ & 0.064 \\
\hline Magnesium (mg) & - & $56.5 \pm 45.9$ & $80.6 \pm 26.3$ & 25.0 (10.4 to 39.7$)$ & 0.001 \\
\hline
\end{tabular}

Values presented as Mean $\pm S D$. and Mean change (95\%CI). p-value corresponds to Paired t-test.

Table 4. Comparison of two regular meals per day without the ONCE renal supplement at aseline and at the end of study

\begin{tabular}{lcccc}
\hline \multicolumn{1}{c}{ Per day } & Baseline & End & $\begin{array}{c}\text { Mean Change } \\
(\mathbf{9 5 \% ( C I )})\end{array}$ & $p$-value \\
\hline Energy $(\mathrm{Kcal})$ & $900.8 \pm 287.7$ & $923.2 \pm 287.6$ & $22.3(-104.8,60.2)$ & 0.585 \\
Energy $(\mathrm{kcal} / \mathrm{kg} /$ day $)$ & $13.9 \pm 4.8$ & $13.9 \pm 4.1$ & $0.05(-12.9,1.2)$ & 0.935 \\
Protein $(\mathrm{g})$ & $38.1 \pm 19.9$ & $41.5 \pm 23.9$ & $3.3(-7.7,1.1)$ & 0.133 \\
Protein $(\mathrm{g} / \mathrm{kg} /$ day) & $0.8 \pm 0.3$ & $0.6 \pm 0.3$ & $0.04(-0.1,0.02)$ & 0.229 \\
Carbohydrate $(\mathrm{g})$ & $126.4 \pm 55.1$ & $120.7 \pm 49.4$ & $-5.6(-7.2,18.5)$ & 0.378 \\
Fat $(\mathrm{g})$ & $26.6 \pm 10.3$ & $30.3 \pm 14.1$ & $3.67(-8.2,0.8)$ & 0.106 \\
\hline
\end{tabular}

Values presented as Mean $\pm S D$. and Mean change (95\%CI). p-value corresponds to Paired t-test.

\section{Energy and Nutrient Intake}

Table 3 shows the mean values for estimated energy and nutrient intake at baseline and at week 4. A significant increase in energy intake from $19.8 \pm 6.1$ to $22.5 \pm 5.3 \mathrm{kcal} / \mathrm{kg} / \mathrm{day}(p=0.005)$, fat intake from $40.7 \pm 14.9$ to $50.9 \pm 15.2 \mathrm{~g} /$ day $(p<0.001)$ and fiber intake from $8.8 \pm 3.2$ to $11.0 \pm 3.7 \mathrm{~g} /$ day $(p<0.001)$ were observed during the study. No significant change was found in dietary protein, carbohydrate, sodium, potassium, calcium and phosphorus intake after intervention except significant increase in magnesium intake [25.0 (95\% CI 10.4 to 39.7$) \mathrm{g} / \mathrm{day}, p=0.001$ ]. We also determined that energy and nutrient intake from regular food ( 2 meals daily) was similar at baseline and at the end of the study (Table 4). 
Table 5. Nutritional, electrolyte, mineral and renal parameters at baseline and at the end of four-week follow-up

\begin{tabular}{|c|c|c|c|c|}
\hline Variables & Baseline & End & $\begin{array}{l}\text { Mean Change } \\
(95 \% \text { CI })\end{array}$ & $p$-value \\
\hline \multicolumn{5}{|c|}{ Nutrition parameters and body compositions } \\
\hline Body weight $(\mathrm{kg})$ & $66.4 \pm 13.6$ & $66.9 \pm 13.3$ & $0.45(0.74$ to 0.84$)$ & 0.021 \\
\hline Body mass index (kg/cm2) & $25.5 \pm 3.5$ & $25.6 \pm 3.4$ & $0.17(0.22$ to 0.32$)$ & 0.026 \\
\hline Serum albumin $(\mathrm{g} / \mathrm{dL})$ & $4.4 \pm 0.3$ & $4.5 \pm 0.3$ & $0.03(-0.12$ to 0.65$)$ & 0.557 \\
\hline Percentage of total body water (\%) & $46.9 \pm 5.9$ & $46.7 \pm 5.5$ & $-0.25(-0.42$ to 0.90$)$ & 0.453 \\
\hline Percentage of body fat $(\%)$ & $30.4 \pm 8.2$ & $30.8 \pm 7.6$ & $0.39(-1.48$ to 0.70$)$ & 0.466 \\
\hline Muscle mass (kg) & $43.9 \pm 10.8$ & $42.6 \pm 10.5$ & $-1.36(-1.38$ to 4.10$)$ & 0.319 \\
\hline Bone mass $(\mathrm{kg})$ & $3.2 \pm 3.7$ & $3.2 \pm 3.8$ & $0.01(-0.09$ to 0.66$)$ & 0.748 \\
\hline $\begin{array}{l}\text { Protein equivalence of total nitrogen } \\
\text { appearance }(\mathrm{g} / \mathrm{kg} / \text { day })\end{array}$ & $0.7 \pm 0.2$ & $0.7 \pm 0.2$ & $-0.06(-0.01$ to 0.12$)$ & 0.095 \\
\hline \multicolumn{5}{|c|}{ Renal function, serum electrolytes and minerals } \\
\hline Blood urea nitrogen $(\mathrm{mg} / \mathrm{dL})$ & $34.6 \pm 11.7$ & $34.3 \pm 11.3$ & $-0.34(-1.64$ to 2.33$)$ & 0.726 \\
\hline Serum creatinine $(\mathrm{mg} / \mathrm{dL})$ & $2.6 \pm 0.6$ & $2.5 \pm 0.6$ & $-0.07(-0.15$ to 0.01$)$ & 0.109 \\
\hline $\begin{array}{l}\text { Estimated glomerular filtration rate } \\
\left(\mathrm{mL} / \mathrm{min} / 1.73 \mathrm{~m}^{2}\right)\end{array}$ & $22.1 \pm 6.0$ & $22.9 \pm 6.3$ & $0.77(-2.56$ to 1.02$)$ & 0.387 \\
\hline Sodium $(\mathrm{mEq} / \mathrm{L})$ & $137.5 \pm 22.6$ & $140.9 \pm 1.7$ & $3.46(-11.50$ to 4.58$)$ & 0.387 \\
\hline Potassium (mEq/L) & $4.6 \pm 0.4$ & $4.5 \pm 0.5$ & $-0.09(-0.05$ to 0.24$)$ & 0.193 \\
\hline Bicarbonate (mg/dL) & $23.8 \pm 2.5$ & $24.3 \pm 2.6$ & $0.55(-1.34$ to 0.25$)$ & 0.171 \\
\hline Calcium (mg/dL) & $9.4 \pm 0.5$ & $9.3 \pm 0.4$ & $-0.02(-0.11$ to 0.16$)$ & 0.718 \\
\hline Phosphorus (mg/dL) & $3.7 \pm 0.5$ & $3.7 \pm 0.5$ & $0.03(-0.18$ to 0.13$)$ & 0.701 \\
\hline Magnesium (mg/dL) & $2.8 \pm 3.6$ & $2.2 \pm 0.2$ & $-0.65(-0.66$ to 1.96$)$ & 0.316 \\
\hline \multicolumn{5}{|c|}{ 24-hr urine protein, electrolytes and minerals } \\
\hline Protein (g/day) & $0.9 \pm 1.1$ & $1.0 \pm 1.3$ & $0.06(-0.22$ to 0.10$)$ & 0.472 \\
\hline Sodium (mEq/day) & $90.4 \pm 36.2$ & $97.7 \pm 67.1$ & $7.37(-31.04$ to 16.30$)$ & 0.530 \\
\hline Potassium (mEq/day) & $17.3 \pm 7.3$ & $17.3 \pm 7.3$ & $-0.01(-2.76$ to 277$)$ & 0.998 \\
\hline Magnesium (mEq/day) & $3.8 \pm 1.8$ & $3.9 \pm 1.7$ & $0.05(-0.62$ to 0.51$)$ & 0.858 \\
\hline Chloride (mEq/day) & $71.4 \pm 34.7$ & $78.7 \pm 71.5$ & $7.33(-34.23$ to 16.57$)$ & 0.582 \\
\hline
\end{tabular}

Values presented as Mean $\pm S D$. and Mean change $(95 \% C I)$. p-value corresponds to Paired t-test.

\section{Nutrition and body compositions}

A significant increase in body weight with a mean difference of 0.45 (95\% CI 0.74 to $0.84, p=0.021) \mathrm{kg}$ and BMI with a mean difference of $0.17(95 \%$ CI 0.22 to $0.32, p=0.026) \mathrm{kg} / \mathrm{cm}^{2}$ were observed after 30 days. No significant changes in serum albumin, PNA and body compositions were found at the study endpoint (Table 5).

\section{Serum and Urine Biochemical Measurement}

At the end of the study, the treatment did not significantly change the concentrations of renal function, serum sodium, potassium, bicarbonate, calcium, phosphorus, and magnesium.
No significant differences were observed in 24-hour urine protein, electrolytes and minerals before and after treatment. During the study, no serious complications were observed especially electrolyte disturbances and fluid overload. At the study's completion, patient compliance, receiving the ONCE Renal supplementation on schedule, was $99.7 \%$

\section{Discussion}

The results of our study showed that the daily use of a 360-kcal ONCE renal supplement for 30 days improved energy, fat, fiber, and body weight among patients with stage IV CKD, indicating 
that the use of these supplement had beneficial effects on dietary nutrient intake without short term electrolytes disturbance.

Loss of appetite, poor food intake, anorexia and vomiting are more common symptoms among patients with advanced CKD; hence, predisposing them to malnutrition. Several studies have indicated that minimum calorie requirements were not met among patients with advanced $\mid \mathrm{CKD}$, despite dietary nutritional counseling. ${ }^{(8)}$ Enriched nutritional supplements might improve dietary intakeandmalnutrition. However, limitedevidence exists pertaining to the impact of nutritional supplementation in preventing malnutrition and improving quality of life among patients with CKD and undergoing dialysis. ${ }^{(12,13)}$ Most clinical guidelines preferred oral nutritional supplements as first line treatment to increase caloric and protein dietary intake at 25 to $30 \mathrm{kcal} / \mathrm{kg} /$ day and 0.55 to $0.6 \mathrm{~g} / \mathrm{kg} /$ day in advanced CKD. ${ }^{(14,15)}$ Our study indicated that the ONCE Renal diet significantly improved energy and fiber intake and maintained nutritional markers among patients with advanced CKD. This study was consistent with results found in other studies and a systematic review demonstrating effectiveness of renal dietary intervention for patients with advanced CKD and dialysis populations. ${ }^{(16-20)}$ Studies are limited concerning the efficacy of specific renal supplement in a long term study and among significantly malnourished patients with CKD .

Medical nutrition therapy by a registered dietitian experienced in predialysis CKDimproved nutrition-related biomarkers, ${ }^{(21)}$, but energy and dietary component targets may be difficult to achieve with dietary counseling alone. ${ }^{(22)}$ An additional benefit of the ONCE Renal supplement is the low amount of protein $(7.2 \mathrm{~g} / 360 \mathrm{kcal})$, sodium ((132 mg/360 kcal), phosphate $(143 \mathrm{mg} /$ $360 \mathrm{kcal})$, potassium $(197 \mathrm{mg} / 360 \mathrm{kcal})$ and magnesium (39 mg/360 kcal) content. As a consequence, serum potassium, magnesium and phosphate did not increase after treatment, which was of significant benefit to patients. Moreover, our study indicated that the ONCE Renal diet supplement instead of 1 regular meal could achieve the therapeutic targets of dietary intake with an average dietary sodium intake of $2.1 \mathrm{~g} /$ day, average 24-hour urine sodium of $98 \mathrm{mEq} / \mathrm{day}$, average dietary potassium intake of $1.2 \mathrm{~g} /$ day, average 24-hour urine potassium of $17 \mathrm{mEq} / \mathrm{day}$, average dietary phosphorus intake of $0.6 \mathrm{~g} /$ day and average dietary magnesium intake of $80 \mathrm{mg} /$ day in addition to dietary counseling. The ONCE Renal supplement did not increase risk of electrolyte abnormality among patients with advanced CKD.

Inadequate energy and excess protein intake were correlated with worsening renal function in $\mathrm{CKD}^{(23)}$ and ensuring compliance is the main target for effective nutritional intervention. ${ }^{(24)}$ Related studies have shown that about 40 to $50 \%$ of patients with CKD follow the recommended diets. ${ }^{(25,26)}$ In contrast to our study, compliance was very good; $99 \%$ of patients complied with the ONCE Renal supplementation for 30 days, improving an average additional caloric intake with low amount of protein $(7.2 \mathrm{~g} / 360 \mathrm{kcal})$. The high percentage of compliance may reflect the type of patient selection in our study in that they received the intervention based on their excellent reputation for nutritional management. Therefore, the ONCE Renal diet was convenient for educated patients with CKD unable to choose an appropriate low protein renal diet to maintain adequate energy intake. However, patient compliance was limited by the relatively short period of follow-up.

The study had a few limitations. First, the study design was not randomized or placebo-controlled. Second, the INMUCAL program could not represent all micronutrients completely, especially magnesium (validity 36.3\%). ${ }^{(28)}$ Therefore, the amount of magnesium was shown lower than usual diets. Furthermore, the study was conducted in an outpatient clinic setting, and a 3-day dietary recall was used to estimate food intake. The validity of this method could be questioned because the day-to-day food intake may have varied, and it may not be representative of a usual diet.

In conclusion, the results provided some beneficial effects of a renal-specific oral nutritional support combined with nutritional counseling among patients with advanced CKD. The ONCE Renal diet improved energy, fiber and magnesium intake without significant short term abnormal electrolyte disturbance. This intervention might require larger studies in other groups of patients with CKD with longer duration of the ONCE Renal supplement. 


\section{ACKNOWLEDGEMENTS}

This study was supported by a grant from Phramongkutklao Hospital and Phramongkutklao College of Medicine, Thai Otsuka Pharmaceutical Co., Ltd. Thailand and the National Science and Technology Development Agency (NSTDA, P-13-00505), Bangkok, Thailand.

\section{CONFLICT OF INTEREST}

The authors declare that they have no competing interests.

\section{DATA AVAILABILITY STATEMENT}

Individual clinical data used to support the findings of this study are available from the corresponding author upon request.

\section{REFERENCES}

1. Kovesdy CP, George SM, Anderson JE, Kalantar-Zadeh K. Outcome predictability of biomarkers of protein-energy wasting and inflammation in moderate and advanced chronic kidney disease. Am J Clin Nutr 2009; 90: 407-14.

2. Kovesdy CP, Anderson JE, Kalantar-Zadeh K. Paradoxical association between body mass index and mortality in men with CKD not yet on dialysis. Am J Kidney Dis 2007; 49: 581-91.

3. Kalantar-Zadeh K, Ikizler TA, Block G, Avram MM, Kopple JD. Malnutrition-inflammation complex syndrome in dialysis patients: causes and consequences. Am J Kidney Dis 2003; 42: 864-81.

4. Ballmer PE, McNurlan MA, Hulter HN, Anderson SE, Garlick PJ, Krapf R. Chronic metabolic acidosis decreases albumin synthesis and induces negative nitrogen balance in humans. J Clin Invest 1995; 95: 39-45.

5. Avesani CM, Cuppari L, Silva AC, Sigulem DM, Cendoroglo M, Sesso R, et al. Resting energy expenditure in pre-dialysis diabetic patients. Nephrol Dial Transplant 2001; 16: 556-65.

6. Cuppari L, de Carvalho AB, Avesani CM, Kamimura MA, Dos Santos Lobao RR, Draibe SA. Increased resting energy expenditure in hemodialysis patients with severe hyperparathyroidism. JAm Soc Nephrol 2004; 15: 2933-9.
7. Kovesdy CP, Kopple JD, Kalantar-Zadeh K. Management of protein-energy wasting in non-dialysis-dependent chronic kidney disease: reconciling low protein intake with nutritional therapy. Am J Clin Nutr 2013; 97 : 1163-77.

8. Kopple JD, Monteon FJ, Shaib JK. Effect of energy intake on nitrogen metabolism in nondialyzed patients with chronic renal failure. Kidney Int 1986; 29: 734-42.

9. Dukkipati R, Kopple JD. Causes and prevention of protein-energy wasting in chronic kidney failure. Semin Nephrol 2009; 29: 39-49.

10. Supasyndh O, Satirapoj B, Seenamngoen S, Yongsiri S, Choovichian P, Vanichakarn S. Nutritional status of twice and thrice-weekly hemodialysis patients with weekly Kt/V > 3.6. J Med Assoc Thai 2009; 92: 624-31.

11. Cano N, Fiaccadori E, Tesinsky P, Toigo G, Druml W, Dgem, et al. ESPEN Guidelines on Enteral Nutrition: Adult renal failure. Clin Nutrition 2006; 25: 295-310.

12. Campbell KL, Ash S, Zabel R, McFarlane C, Juffs P, Bauer JD. Implementation of standardized nutrition guidelines by renal dietitians is associated with improved nutrition status. Journal of renal nutrition : the official journal of the Council on Renal Nutrition of the National Kidney Foundation. 2009; 19: 136-44.

13. Sharma M, Rao M, Jacob S, Jacob CK. A controlled trial of intermittent enteral nutrient supplementation in maintenance hemodialysis patients. J Ren Nutr 2002; 12: 229-37.

14. Kidney Disease Outcomes Quality I. K/ DOQI clinical practice guidelines on hypertension and antihypertensive agents in chronic kidney disease. American journal of kidney diseases : the official Journal of the National Kidney Foundation. 2004; 43(5 Suppl 1): S1-290.

15. Cano NJ, Aparicio M, Brunori G, Carrero JJ, Cianciaruso B, Fiaccadori E, et al. ESPEN Guidelines on Parenteral Nutrition: adult renal failure. Clin Nutr 2009; 28: 401-14.

16. Chang JH, Kim DK, Park JT, Kang EW, Yoo $\mathrm{TH}$, Kim BS, et al. Influence of ketoanalogs supplementation on the progression in chronic kidney disease patients who had training on low-protein diet. Nephrology. 2009; 14: 750-7. 
17. Teplan V, Schuck O, Knotek A, Hajny J, Horackova M, Skibova J, et al. Effects of low-protein diet supplemented with ketoacids and erythropoietin in chronic renal failure: a long-term metabolic study. Annals of transplantation : quarterly of the Polish Transplantation Society 2001; 6: 47-53.

18. Caglar K, Fedje L, Dimmitt R, Hakim RM, Shyr Y, Ikizler TA. Therapeutic effects of oral nutritional supplementation during hemodialysis. Kidney Int 2002; 62: 1054-9.

19. Satirapoj B, Prapakorn J, Punpanich D, Pongsuparbchon C, Supasyndh O. The effect of ONCE Renal on minerals and electrolytes in predialysis patients with chronic kidney disease. Int J Nephrol Renovasc Dis 2016; 9: 81-6.

20. Stratton RJ, Bircher G, Fouque D, Stenvinkel $\mathrm{P}$, de Mutsert R, Engfer M, et al. Multinutrient oral supplements and tube feeding in maintenance dialysis: a systematic review and meta-analysis. Am J Kidney Dis 2005; 46: 387-405.

21. de Waal D, Heaslip E, Callas P. Medical Nutrition Therapy for Chronic Kidney Disease Improves Biomarkers and Slows Time to Dialysis. J Ren Nutr 2016; 26: 1-9.

22. Moore H, Reams SM, Wiesen K, Nolph KD, Khanna R, Laothong C, et al. National Kidney
Foundation Council on Renal Nutrition survey: past-present clinical practices and future strategic planning. J Ren Nutr 2003; 13: $233-40$.

23. Huang MC, Chen ME, Hung HC, Chen HC, Chang WT, Lee $\mathrm{CH}$, et al. Inadequate energy and excess protein intakes may be associated with worsening renal function in chronic kidney disease. J Ren Nutr 2008; 18: 187-94.

24. Beto JA, Schury KA, Bansal VK. Strategies to promote adherence to nutritional advice in patients with chronic kidney disease: a narrative review and commentary. Int J Nephrol Renovasc Dis 2016; 9: 21-33.

25. Aparicio M, Bellizzi V, Chauveau P, Cupisti A, Ecder T, Fouque D, et al. Do ketoanalogues still have a role in delaying dialysis initiation in CKD predialysis patients? Semin Dial 2013; 26: 714-9.

26. Garneata L, Stancu A, Dragomir D, Stefan G, Mircescu G. Ketoanalogue-Supplemented Vegetarian Very Low-Protein Diet and CKD Progression. J Am Soc Nephrol 2016; 27: 2164-76.

28. Institute of Nutrition, Mahidol University. Nutrients calculation software: INMUCALNutrients V.3.2 Database version NB.3, Thailand, 2018. 